\title{
PUDENDAL NERVE BLOCK IN MALE GOATS: COMPARISON OF ISCHIORECTAL FOSSA AND ISCHIAL ARCH APPROACHES USING LOW VOLUME 1\% LIGNOCAINE HYDROCHLORIDE
}

\author{
Mujeebur Rehman Fazili', Nida Handoo², Mohd Younus Mir², Beenish Qureshi \\ ${ }^{1}$ Veterinary Clinical Complex, Faculty of Veterinary Sciences \& Animal Husbandry, \\ Shere Kashmir Universityof Agricultural Sciences \& Technology of Kashmir, Shuhama, \\ Srinagar, Kashmir, India \\ ${ }^{2}$ Division of Veterinary Surgery \& Radiology, Faculty of Veterinary Sciences \& Animal \\ Husbandry, Shere Kashmir University of Agricultural Sciences \& Technology of \\ Kashmir, Shuhama, Srinagar, Kashmir, India
}

Received 26 July 2015; Received in revised form 24 September 2015; Accepted 9 November 2015

\begin{abstract}
Thirty (30) adult male goats were injected xylazine $(0.05 \mathrm{mg} / \mathrm{kg}$, IM) and randomly divided into three equal groups. Internal pudendal nerve block was tried using $3.5 \mathrm{ml}$ (on each side) of $1 \%$ lignocaine hydrochloride byischiorectal fossa or ischial arch approaches in goats from Group 1 and Group 2 respectively, 15 minutes after giving xylazine. Inadvertent puncture of the rectal wall and prick to the finger placed in the rectum was experienced once in Group 1 animal. None of the animals showed protrusion of the penis without manual manipulation. Prolapse of the prepucial ring was noticed in three animals from Group 1 and two each from Group 2 and 3. The application of mild manual push percutaneously resulted in the exposure of the penis in eight and six animals belonging to Group 1 and Group 2 respectively, 15 minutes after injection of the local anaesthetic. Statistically significant $(\mathrm{P}>0.05)$ difference between Group 1 and 2 values was detected only once at 90 minutes following injection of the local anaesthetic. The block lasted longer in animals of Group 1. The exposed organ was flaccid and insensitive. The organ retracted into the prepucial cover within five minutes of its release in all the animals. The penile exposure could not be achieved by similar manipulation in any of the Group 3 animals. From this study it was concluded that the ischiorectal fossa approach is cumbersome and may lead to inadvertent punctures, but the block develops in more number of animals for a longer period than with the ischial arch approach. The outcome of the two techniques did not show statistically significant $(\mathrm{P}>0.05)$ difference for most of the assessment period. Reducing the concentration of lignocaine hydrochloride may reduce the chances of continued relaxation of the penis beyond the required period and also the drug toxicity. However, studies using larger volume of $1 \%$ lignocaine hydrochloride may be undertaken for short term exposure of the penis without manual manipulation.
\end{abstract}

Key words: pudendal nerve block, goat, penis, prepuce, ischiorectal, ischial arch

\section{INTRODUCTION}

Bilateral pudendal nerve block is used in the male ruminants for penile analgesia along with its relaxation. Examination and excision of the urethral process or management of penile and prepucial pathology like infections, tumours, trauma and

Corresponding author: Dr. Mujeebur Rehman Fazili, $\mathrm{PhD}$

E-mail address: fazili mr@yahoo.co.in

Present address: Veterinary Clinical Complex, Faculty of Veterinary

Sciences \& Animal Husbandry, Shere Kashmir University of Agricultural

Sciences \& Technology of Kashmir, Shuhama, Srinagar, Kashmir, India

Pin code: 91-190006

Phone: ++91-0941995830

Copyright: (C) 2015 Fazili M.R. This is an open-access article published under the terms of the Creative Commons Attribution License which permits unrestricted use, distribution, and reproduction in any medium, provided the original author and source are credited.

Competing Interests: The authors have declared that no competing interests exist.

Available Online First: 17 November 2015

Published on: 15 March 2016

http://dx.doi.org/10.1515/macvetrev-2015-0064 pizzle rot are some of the common indications of the block in small ruminants (1). The pudendal nerve arises from the ventral branches of the second to fourth sacral nerves and provides motor supply to the retractor penis muscle and, via the dorsal nerve of penis, sensory innervation of the penis (2). The internal pudendal nerve block using an ischiorectal fossa approach was described for the first time by Larson (3) in bulls. An alternate lateral approach for rams was developed by McFarlane (4). El-Kammar and Alsafy (5) described the ischial arch approach in goats. In addition to the maintenance of the tail tone, the most important advantage of the internal pudendal nerve desensitization over lumbosacral epidural analgesia is the maintenance of the motor power of the hind limbs (6). The undue delay in the retraction of the protruded penis beyond the period required for clinical examination or surgery and 
the consequent risk of trauma to this organ (7) is a serious concern precluding the frequent use of this procedure in clinical practice. Perusal of the available literature indicates very few reports of the use of pudendal nerve block in goats. This study was therefore planned to compare two techniques of this block in male goats. Use of low volume of the $1 \%$ lignocaine hydrochloride was hypothesized to reduce the duration of penile protrusion and the risk of drug toxicity.

\section{MATERIAL AND METHODS}

Thirty clinically healthy adult male goats of different breeds (Bakerwal, Pashmina and their cross) were randomly divided into three equal groups. The goats were maintained under standard welfare guidelines at Mountain Research Centre for Sheep and Goats of the University. The study was undertaken after the Institutional Animal Ethics Committee (IAEC) approved the design of the work. All animals were administered xylazine $(0.05 \mathrm{mg} / \mathrm{kg}$, IM). They were let loose in the paddock for 15 minutes and then restrained in a standing posture. Two assistants were required, one holding the head of the goat and the other the hind quarters and the tail.

Following the routine aseptic measures, the goats of Group 1 were subjected to the pudendal nerve block using $3.5 \mathrm{ml}$ (on each side) of $1 \%$ lignocaine hydrochloride ( $2 \%$ preparation diluted with equal volume of normal saline) following the ischiorectal fossa technique (Fig. 1) described by Larson (3). The finger of the gloved hand was introduced into the rectum of these goats and directed laterally to detect the slit-like lesser sacrosciatic foramen, 4.0 to $5.0 \mathrm{~cm}$ inside the anal opening. Hypodermic $(18-\mathrm{G})$

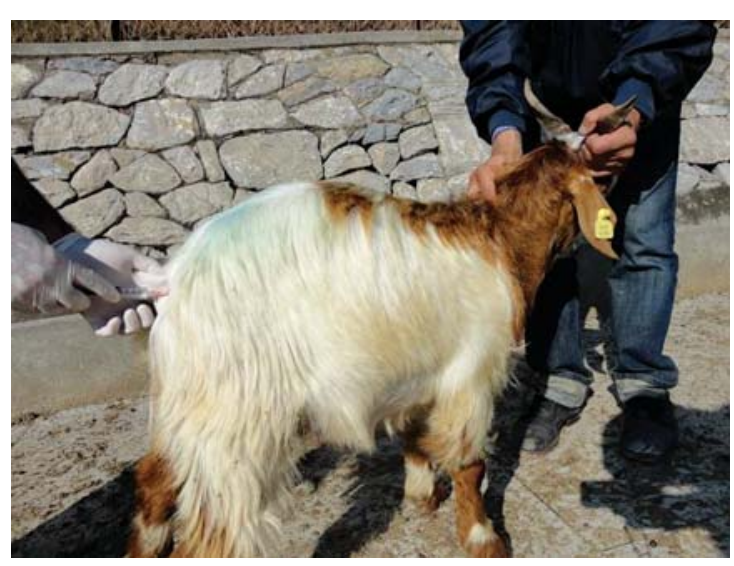

Figure 1. Ischiorectal fossa approach for pudendal nerve block in a goat: Left hand first finger in the rectum guiding the hypodermic needle (inserted via right ischiorectal fossa) to the sacrosciatic foramen needle was introduced percutaneously in the deepest depression of the ishiorectal fossa and guided by the finger inside the rectum of the animal to the sacrosciatic foramen for deposition of the local anaesthetic. The procedure was similarly repeated on the contralateral side of the goat. In Group 2 goats the ischial arch approach (5) was followed for deposition of $3.5 \mathrm{ml}$ lignocaine hydrochloride (1\%) on each side (Fig. 2). The needle (18-G) was inserted $2.0 \mathrm{~cm}$ dorsomedial to the ischial arch and $2.0 \mathrm{~cm}$ lateral to the anus. It was advanced in the medioventral direction till it stroked the ischial arch and the local anaesthetic deposited. The Group 3 goats were not injected a local anaesthetic.

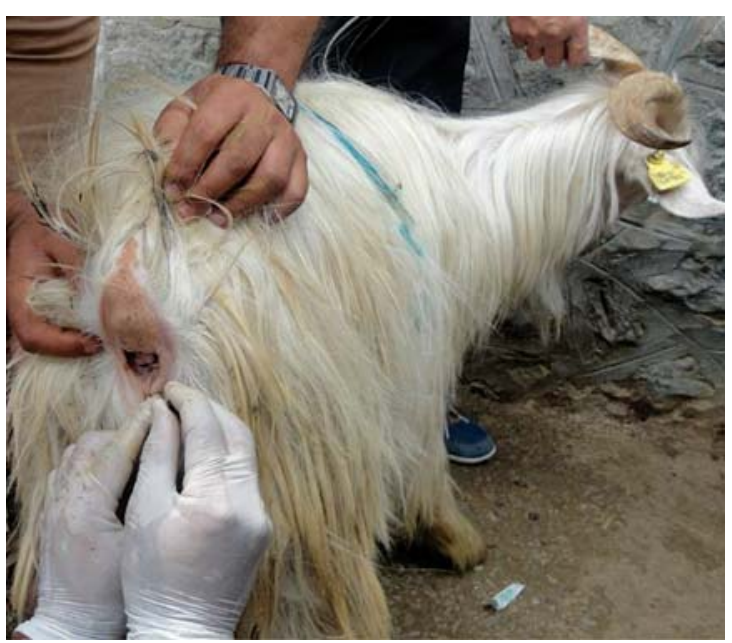

Figure 2. Ischial arch approach for pudendal nerve block in a goat: G-18 hypodermic needle inserted dorsomedial to the right ischial arch and lateral to the anus

The animals were let loose in the open paddock and observed continuously for protrusion of the prepuce and penis up to 2 hours. All of them were restrained 15 minutes after xylazine administration in a standing posture. While sitting on the right side of the animal, the penis was held percutaneously with the left hand and pushed cranially with mild manual force. The right hand was simultaneously used to push the prepucial sheath in the opposite direction so that the penis could be exposed. The goats belonging to Group 1 and Group 2, but not the Group 3 goats, were injected local anaesthetic for blocking their pudendal nerves. All the animals were repeatedly restrained in a standing posture 15 minutes, 30 minutes, 60 minutes, 90 minutes and 120 minutes after injection of the local anaesthetic (Group 1 and Group 2) or xylazine (Group 3) for exposure of the penis following the above mentioned procedure.

The body weight values of the goats belonging to the various groups are presented as mean with 
standard deviation (mean $\pm \mathrm{SD})$ after application of the one-way ANOVA. The outcome of the approaches for inducing pudendal nerve block was analysed by the Fisher's Exact Test. Statistically significant differences were accepted at $\mathrm{P}<0.05$.

\section{RESULTS}

The outcome of the pudendal nerve block in male goats has been presented in Table 1 .

The mean \pm S.D body weight of the goats included in Group 1 was $29.80 \pm 6.03 \mathrm{~kg}$, Group $2,31.50 \pm 7.26 \mathrm{~kg}$ and Group 3,30.10 $\pm 5.74 \mathrm{~kg}$. The mean values between the groups did not differ significantly $(\mathrm{P}>0.05)$.

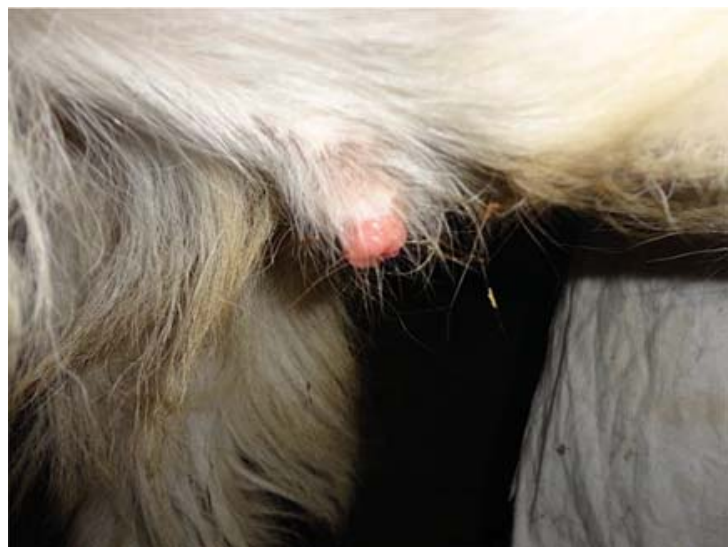

Figure 3. Relaxed prepucial ring of a goat after xylazine administration

Table1. Outcome of the pudendal nerve block using $1 \%$ lignocaine hydrochloride $(3.5 \mathrm{ml} / \mathrm{side})$ in male goats

\begin{tabular}{lllllllll} 
Male Goats & \multicolumn{7}{c}{ Time interval (minutes) } \\
\hline Groups & $\begin{array}{l}\text { Body weight } \\
(\mathbf{m e a n} \pm \text { S.D) }\end{array}$ & $\mathbf{N}$ & $\mathbf{0}$ & $\mathbf{1 5}$ & $\mathbf{3 0}$ & $\mathbf{6 0}$ & $\mathbf{9 0}$ & $\mathbf{1 2 0}$ \\
\hline I & $29.80 \pm 6.03^{\mathrm{a}}$ & 10 & $\mathrm{nil}^{\mathrm{x}}$ & $8^{\mathrm{y}}$ & $8^{\mathrm{y}}$ & $9^{\mathrm{y}}$ & $9^{\mathrm{y}}$ & $6^{\mathrm{y}}$ \\
II & $31.50 \pm 7.26^{\mathrm{a}}$ & 10 & $\mathrm{nil}^{\mathrm{x}}$ & $6^{\mathrm{y}}$ & $7^{\mathrm{y}}$ & $6^{\mathrm{y}}$ & $3^{\mathrm{z}}$ & $3^{\mathrm{y}}$ \\
III & $30.10 \pm 5.74^{\mathrm{a}}$ & 10 & nil $^{\mathrm{x}}$ & $\mathrm{nil}^{\mathrm{x}}$ & $\mathrm{nil}^{\mathrm{x}}$ & $\mathrm{nil}^{\mathrm{x}}$ & nil $^{\mathrm{x}}$ & nil $^{\mathrm{x}}$ \\
\hline
\end{tabular}

Values with different superscripts vary significantly $(\mathrm{P}>0.05)$ between the groups.

Xylazine induced sedation was mild so that it could allow injection of the local anaesthetic without frequent movement of the animals. Most of them remained standing throughout the observation period however, eight showed tendency to lie down after the first 15 minutes of administration of xylazine. Five urinated and three showed dribbling of saliva for a variable period.

The passage of the lubricated gloved finger into the rectum of the animals belonging to Group 1 was resisted by the animals in the beginning of the procedure. Inadvertent puncture of the rectal wall and prick to the finger placed in the rectum was experienced once. Accidental puncture of a blood vessel (indicated by backflow of blood drops through the needle hub) also occurred once while guiding the tip of the percutaneously inserted needle.

None of the animals of any group showed prolapse of the penis without manipulation throughout the observation period. However, three animals from Group 1 showed prolapse of the prepucial ring from 60 minutes to 90 minutes post injection. In Group 2 and Group 3 goats, two animals developed prepucial prolapse at 15 minutes/30 minutes that continued up to 60 minutes (Fig. 3).
In none of the animals included in the study, the penis could be exposed manually immediately before xylazine administration and also 15 minutes later. In Group 3 goats, the organ could not be exposed even beyond that period.

In eight of the ten goats belonging to Group 1, the glans penis could be exposed manually from 15 minutes to 90 minutes after injection of the local anaesthetic (Fig. 4). One more goat from this group also responded at 60 minutes and 90 minutes. At 120 minutes post-injection, the exposure of the penis was possible in six animals only.

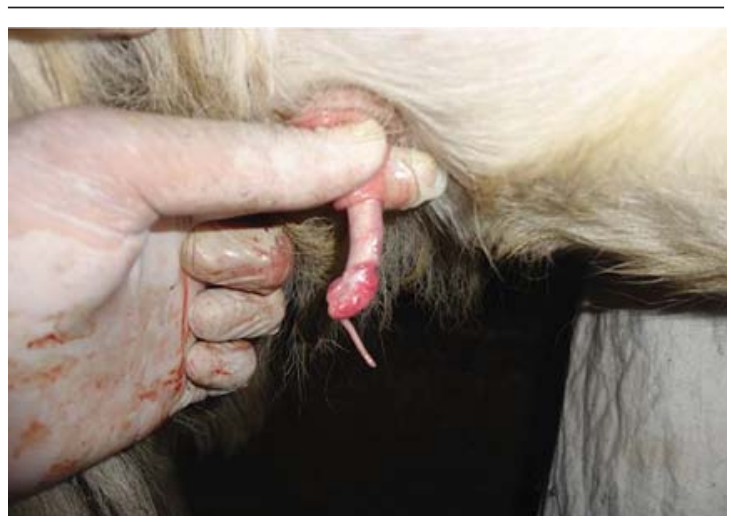

Figure 4. Extruded penis and urethral process in a standing goat after pudendal nerve block 
In Group 2 goats, the penis could be exposed in six animals at 15 minutes and 60 minutes, seven at 30 minutes and three animals only during last two examinations.

The outcome of the goats belonging to Group 1 and Group 2 differed significantly with that of Group 3 animals at all assessment intervals. However, the outcome between the first two groups showed no significant difference $(\mathrm{P}>0.05)$ except at 90 minutes following injection of the local anaesthetic. At this interval, the Group 1 outcome was significantly better than that of Group 2 animals.

In all the animals of both groups, wherein the penis could be exposed, the manual holding and mild traction of the urethral process or glans penis did not result in local or general reaction indicative of pain or discomfort to the animal. The penis retracted into the prepucial cover within five minutes of its release in all of these animals.

\section{DISCUSSION}

Relaxation and analgesia of the penis in male animals is certain following epidural injection of the local anaesthetic. However in practice, the prolonged recumbency as a serious objection to this technique cannot be ignored (8).

The temperament of the goat to resist physical restrain often demands use of a sedative. Xylazine is used as an effective calming agent in ruminants. It is accompanied by some muscle relaxant effect, but unlike phenothiazine derivatives, it has not been found to cause relaxation of the penis in male animals. The low dose $(0.05 \mathrm{mg} / \mathrm{kg}$, IM) of the agent used in the present study provided standing sedation in majority of the goats. The ones that showed tendency of lying down got up when approached for examination at repeated intervals. Major effects of the xylazine develop within 10 to 15 minutes after IM injection (6). The goats included in Group 1 and Group 2 were therefore injected local anaesthetic 15 minutes after xylazine administration.

They were injected low volume $(3.5 \mathrm{ml} / \mathrm{side})$ dilute (1\%) lignocaine hydrochloride. Different techniques for desensitization of internal pudendal nerves in small ruminants, using $3.0 \mathrm{ml}$ to $10.0 \mathrm{ml}$ of $2 \%$ lignocaine hydrochloride (with or without 1:100000 adrenaline) on either side have been described $(3,5,6)$. McFarlane (4) used $7.0 \mathrm{ml}$ of a $2 \%$ or $5.0 \mathrm{ml}$ of a $5 \%$ procaine hydrochloride solution in ovine. It has been found that increasing the dose prolongs the duration of the block (5).

In this study, 2\% lignocaine hydrochloride preparation was diluted with equal volume of normal saline immediately before its use to reduce the 114 total dose of the injected drug. Systematic toxicity is a potential complication in small ruminants, so the limited dosage and diluted solutions of xylocaine hydrochloride $2 \%$ in nerve blocking has been advocated $(9,10)$. Restricting the initial administration dose of lignocaine hydrochloride to $6.0 \mathrm{mg} / \mathrm{kg}$ is considered safe in these species (8).

The rectal wall puncture in a goat and injury to the finger of the anaesthetist occurred once during an ischiorectal fossa approach. The danger of puncturing the finger is obvious in such procedures, as the needle is directed by per rectal palpation to locate the appropriate landmarks (11). This places surgeons at high risk for accidentally puncturing their fingers with the needle particularly when the animal moves during the procedure. The ischial approach does not require rectal palpation, it is therefore safer on this account.

Desired results were obtained in eight of the animals in Group 1 and six of those included in Group 2, when examined at 15 minutes following injection of the local anaesthetic. One more goat from each group responded later. The exposed penis was flaccid and insensitive when held manually and pulled lightly. Better outcome in the Group 1 animals (indicated by more number responding positively for longer period) was possible due to the exact identification of the pelvic landmarks by rectal palpation of the injection site. In cattle, 38 of the 40 cattle subjected to this block by the lateral approach obtained relaxation and anaesthesia (4).

None of the animals included in our study showed protrusion of the penis without manipulation. In the animals where the organ was exposed manually, it returned into the prepucial cover within 5 minutes after its release, thus avoiding the risk of injury to it. Using a $2 \%$ preparation of the local anaesthetic, the penis continues to hang outside from one and half to four hours $(3,5)$. In order to avoid trauma of the protruded penis, this delay necessitates manual retraction of penis into the prepuce and application of a tape or purse string suture around the prepucial orifice (7).

\section{CONCLUSION}

From the study it is concluded that the ischiorectal fossa approach is cumbersome and may lead to 3, 5, 6 inadvertent punctures. However, the block develops in a higher number of male goats for a longer period than with the ischial arch approach. Reducing the concentration of the lignocaine hydrochloride may avoid the major disadvantage of protracted relaxation of the penis and also the chances of drug toxicity. However, studies 
using larger volume than used in this study of $1 \%$ lignocaine hydrochloride may be undertaken for obtaining short-term exposure of the penis without manual manipulation.

\section{ACKNOWLEDGEMENT}

The authors express their gratitude to Dr. Z.A Pampori, Senior Scientist, Mountain Research Centre for Sheep and Goats, Prof. R.A Shah, Head Division of Animal Biotechnology and Prof. B.A. Moulvi Head, Division of Veterinary Surgery \& Radiology, Faculty of Veterinary Sciences \& AH, SKUAST-K for providing animals and the facilities required to undertake the study.

\section{REFERENCES}

1. Galatos, A.D. (2011). Anesthesia and analgesia in sheep and goats. Vet. Clin. Food Anim. Pract. 27, 47-59.

http://dx.doi.org/10.1016/j.cvfa.2010.10.007

PMid:21215889

2. Gilbert, R.O., Fubini, S.L. (2004). Surgery of the bovine reproductive system and urinary tract. In: Fubini, S.L \& Ducharme, N.G. (Ed.), Farm animal surgery (pp. 353-354). First edition, Elsevier (USA), St. Louis

3. Larson, L.L. (1953). The internal pudendal (pudic) nerve block for anaesthesia of the penis and relaxation of the retractor penis muscle. J. Am. Vet. Med. Assos. 123, 18-27.

PMid:13061360

4. McFarlane, I.S. (1963). The lateral approach to pudendal nerve block in the bovine and ovine. J. S. African Vet. Med. Ass. 34, 73-76.

5. El-Kammar, M.H., Alsafy, M.A. (2006). Pudendal nerve blockage: Surgical and topographical anatomical study in goat. Kafr El-Sheikh Vet. Med. J. 4, 1011-1030.

6. Tranquilli, W.J., Thurmon, J.C., Grimm, K.A. (2007). Lumb and Jone's veterinary anesthesia and analgesia (pp. 662-663). Fourth edition. Iowa: Blackwell Publishing, USA

7. Elmore, R.G. (1981). Food-animal regional anesthesia. Edwardsville, KS, Veterinary Medicine Publishing

8. Clarke, K.W., Trim, C.M., Hall, L.W. (2014). Veterinary Anaesthesia. (pp.319, 325-326, 347). Eleventh edition. London: Saunders Elsevier, England
9. Gray, P.R., McDonnell, W. (1986). Anaesthesia in sheep and goat. Part1. Local analgesia. Compend. Contin.Educ. 8, S3.

10. Turner, S.A., Mellwaraith, W.C. (1989). Techniques in large animal surgery. Lea \& Febiger (Ed). Third edition, Philladelphia, London

11. Abdi, S., Shenouda, P., Patel, N., Saini, B., Bharat, Y., Calvillo, O. (2004). A novel technique for pudendal nerve block. Pain Physician. 7, 319-322.

PMid:16858468

Please cite this article as: Fazili M.R., Handoo N., Mir M.Y., Qureshi B. Pudendal nerve block in male goats: comparison of ischiorectal fossa and ischial arch approaches using low volume 1\% lignocaine hydrochloride. Mac Vet Rev 2016; 39 (1): 111-115. http://dx.doi.org/10.1515/macvetrev-2015-0064 